Farum

Sociológico

\section{Forum Sociológico}

Série II

39 | 2021

Covid-19: Acesso a direitos, desigualdades sociais e (re)arranjos institucionais no controle da pandemia em Portugal e no Brasil

\title{
Covid-19 em Portugal : A liberdade religiosa na era secular
}

Covid-19 in Portugal : Religious freedom in the secular age

Jorge Botelho Moniz

\section{OpenEdition}

Journals

Edição electrónica

URL: https://journals.openedition.org/sociologico/9832

DOI: 10.4000/sociologico.9832

ISSN: 2182-7427

Editora

CICS.NOVA - Centro Interdisciplinar de Ciências Sociais da Universidade Nova de Lisboa

Edição impressa

Paginação: 9-17

ISSN: 0872-8380

\section{Refêrencia eletrónica}

Jorge Botelho Moniz, «Covid-19 em Portugal : A liberdade religiosa na era secular», Forum Sociológico [Online], 39 | 2021, posto online no dia 23 novembro 2021, consultado o 29 março 2022. URL: http:// journals.openedition.org/sociologico/9832 ; DOI: https://doi.org/10.4000/sociologico.9832 


\title{
COVID-19 EM PORTUGAL: A LIBERDADE RELIGIOSA NA ERA SECULAR
}

\section{COVID-19 IN PORTUGAL: RELIGIOUS FREEDOM IN THE SECULAR AGE}

https://doi.org/10.4000/sociologico.9832

\section{Jorge Botelho Moniz}

Universidade Lusófona, Faculdade de Ciências Sociais, Educação e Administração (FCSEA), Centro de Investigação em Política, Economia e Sociedade (CIPES), Lisboa, Portugal. ORCID: https://orcid.org/0000-0002-1782-8037

\begin{abstract}
Resumo
Este trabalho analisa o impacto das restrições à liberdade religiosa, provocadas pelo estado de emergência sanitária, ligado à pandemia da covid-19, durante o primeiro período de confinamento em Portugal. Ao partir do marco teórico da era secular e secularidade, esta investigação permite interpretar, através de uma análise qualitativa, hipotético-dedutiva, o lugar da religião em sociedades marcadas por culturas de secularidade. Conclui-se que a normalização da subordinação de valores e práticas religiosas aos da esfera política, evidenciada pela hierarquização de atividades essenciais e não-essenciais, e a sua promoção através da autossecularidade esvaziam a presença da religião no espaço público e ajudam no avanço de uma cultura de secularidade.
\end{abstract}

Palavras-chave: secular, secularidade, liberdade religiosa, covid-19

\begin{abstract}
This paper analyses the impact of restrictions on religious freedom, caused by the state of health emergency, related to the COVID-19 pandemic, during the first period of lockdown in Portugal. Against the theoretical backdrop of the secular age and secularism, this research allows for the interpretation of the place of religion in societies marked by cultures of secularity through a qualitative, hypothetical-deductive, analysis. It concludes that the normalisation of the subordination of religious values and practices to those of the political sphere, highlighted by the hierarchization of essential and non-essential activities, and its promotion through self-secularity empties the presence of religion in the public sphere and helps the development of a culture of secularity.
\end{abstract}

Keywords: secular, secularity, religious freedom, COVID-19

\section{Introdução}

O estado de emergência sanitária, ligado à pandemia da covid-19 e decretado na maioria dos países europeus, levou a uma contração rápida e abrupta para o espaço doméstico das esferas da vida pública, pelas quais os indivíduos se habituaram a viver. O confinamento, imposto para conter ou limitar a propagação do vírus, criou uma situação sem precedentes, sobretudo em termos de consequências para as liberdades públicas e direitos fundamentais. Em particular, a liberdade religiosa, entendida na sua dimensão coletiva, foi restringida durante esse período para limitar a propagação do vírus.
Em tempos normais, religião, direito e Estado coexistem numa teia de relações complexas. As crises tendem, porém, a exacerbar tensões e conflitos, e um fenómeno como o da covid-19 - a primeira pandemia global a afetar a era secular no Ocidente pós-cristão - teve o condão de gerar uma situação sem precedentes ao nível da restrição da liberdade religiosa no continente europeu. O modo como os sistemas legais responderam à emergência pandémica, desde a interrupção completa do exercício do culto religioso coletivo até ao reconhecimento de formas mais flexíveis de acomodação religiosa, captou a atenção dos cientistas sociais. Por exemplo, os números especiais do Journal of Law, Religion and State (vol. 8, n.o 2-3, 2020) sobre religião, 
Estado e covid-19; da Revista General de Derecho Canonico y Derecho Eclesiastico del Estado (n. ${ }^{\circ}$ 54, 2020), sobre covid-19 e liberdade religiosa na Europa; e o volume 10, n. ${ }^{\circ} 1$, da Laws com artigos sobre o mesmo tema.

O foco do estado da arte na Europa patenteia o excecionalismo europeu (Berger, Davie \& Fokas, 2008). Com efeito, a análise dos impactos das medidas governamentais torna-se mais relevante num continente onde persiste um padrão de separação com cooperação entre Estado e religiões e, por consequência, um espírito de diálogo, negociação e permanentes (re)definições do espaço público e simbólico de ambos.

Neste contexto, uma forma de se lograrem ganhos epistemológicos, ao nível do estudo das relações Estado-religiões, é através da investigação das práticas políticas e jurídicas atualmente existentes. Assim sendo, este artigo propõe-se examinar o impacto das restrições da covid-19 no exercício da liberdade religiosa em Portugal, na primeira fase do confinamento (de março a maio de 2020) - o "período em que foi mais intensa a limitação (proibição) de realização da liberdade de culto" (Raimundo, Adragão, Leão \& Ramalho , 2020, p. 19). Esta escolha prende-se com cinco motivos: i) sociorreligioso: no contexto europeu, o país é um caso de imobilismo religioso e de predominância dos sem religião, como principal alternativa ao catolicismo; ainda que, ii) no seio da sua própria modernidade, tenha sofrido consequências dos fenómenos da secularização (Moniz, 2021); iii) tipologia de relacionamento Estado-religiões: Portugal está perto dos conceitos de twin tolerations (tolerâncias gémeas) e principled distance (distância por princípio); iv) no tocante às medidas de combate à pandemia, as restrições ao culto religioso foram consideradas "elevadas", quando comparadas com os demais países europeus (The Conversation, 2020); e v) o facto de não existirem ainda investigações que problematizem este fenómeno no país, em particular nas áreas da sociologia e da ciência política.

À luz dos marcos teóricos da era secular (Taylor, 2007) e das culturas de secularidade (Wohlrab-Sahr \& Burchardt, 2012), analisar-se-á como a crise pandémica enfatizou os desafios legais, políticos e socioculturais e deu origem a uma tensão entre direitos concorrentes, exacerbando a tensão entre políticas públicas religiosamente neutras e reivindicações de acomodação religiosa. Por conta da restrição de atividades no espaço público, nomeadamente celebrações religiosas, Portugal afigura-se como um laboratório epistemologicamente útil para se perceber como a liberdade religiosa e, por extensão, os valores religiosos são geridos pelos Estados na era secular.

\section{Era secular e culturas de secularidade}

Vivemos numa era secular, afirmou Charles Taylor (2007) num dos mais célebres trabalhos filosóficos da década de 2000. Ou seja, vivemos numa etapa da idade contemporânea na qual uma estrutura imanente das ordens cósmica, social e moral opera como se o sagrado não existisse ou como se fosse oposto aos processos de amadurecimento, crescimento e emancipação humana. Esta estrutura é a "ordem natural" das sociedades modernas, "um mundo 'imanente', em oposição a um possível 'transcendente'"' (Taylor, 2007, p. 542).

$\mathrm{Na}$ linha de Berger (1990 [1967], 1979), o argumento tayloriano advoga que nas sociedades modernas dificilmente se consegue manter a conceção de que a crença religiosa é central para a ordem social. Pelo contrário, em alguns meios, o secular tornou-se a "solução por defeito" (Taylor, 2007, p. 12-13). O efeito fragilizador dos diferentes elementos das sociedades modernas terá como resultado amiúde "inevitável" (Ibidem, p. 532) o recuo da religião no espaço público. Apesar de reconhecer, inspirado no trabalho de Casanova (1994), que o religioso manterá um certo protagonismo no espaço público, Taylor entende que a competição religioso-secular é um terreno desnivelado e com predomínio de princípios duma ordem moral moderna secular.

As formas institucionais e centralizadas de religião são, portanto, menos capazes do que no passado de influenciar as ações dos indivíduos. Por um lado, Pace (2017) defende que isso pode ser justificado através duma abordagem sistémica luhmianna (Luhmann, 2013 [1998]) que vê a religião como um sistema de relações estabelecidas com um determinado meio. O argumento básico é que, pela coincidência dos fenómenos de diferenciação funcional e de regulação ou controlo da religião, as suas formas institucionais tradicionais sofrem uma perda relativa de relevância social. Por outro lado, Bruce $(2011,2014)$ assevera que essa diminuição do significado social da religião institucional e tradicional deriva da falta de consenso social, uma das suas principais bases de sustentação. O proselitismo religioso, de nível macro (institucional), tornou-se cada vez menos capaz de cativar os indivíduos, no sentido da conversão ou conservação de fiéis. Por seu turno, a contínua afirmação societal (através de interações quotidianas), de nível micro, passou a ser a sua forma mais influente de persuasão. Contudo, considerando o grau de secularidade das sociedades, essa persuadição passou, frequentemente, a ser efetuada em torno de valores e práticas seculares.

As mutações são consequência da afirmação e hegemonia de princípios seculares, como a igualdade e a liberdade, que visam "substituir os religiosos" (Bruce, 2014, p. 192); dum esvaziamento da religião no espaço público, nomeadamente ao nível do 
"controlo das interações quotidianas" (Bruce, 2011, p. 37) e, por conseguinte, duma agudização da crise das suas estruturas de plausibilidade, relatada por Berger (1990 [1967]); e duma relativização das crenças, pois a diversidade e a competição entre cosmovisões religiosas dificulta que alguma se assuma como a verdadeira.

A prescrição desta cultura torna-a dominante. Passa a haver mais consenso e autoridade em torno de princípios e soluções seculares. Afirma-se a força deste poder ideológico e simbólico na promoção de mensagens culturais ou políticas específicas ou na inculcação de princípios particulares e na sua naturalização ou interiorização. O político passa, não só, a determinar o conjunto de regras em torno das quais a sociedade se organiza, mas também a enquadrá-lo, estabelecendo os próprios princípios e práticas através das quais as relações societais se compreendem e experienciam.

Esta ideia geral pode ser entendida à luz do conceito de hegemonias seculares de Wohlrab-Sahr e Burchardt (2012). Os autores, ao escreverem sobre as secularidades múltiplas, descrevem as formas de distinção e institucionalização das diferenciações entre o religioso e outras esferas sociais (consideradas não religiosas), que privilegiam as soluções do Estado moderno e as ideias (seculares) que o fundam. Para os autores, os Estados e as sociedades modernas têm uma série de problemas societais específicos que são entendidos como os seus problemas de referência. Existem quatro problemas de referência: a liberdade individual, relativamente aos grupos sociais dominantes (religiosos ou não religiosos); a diversidade religiosa e o seu conflito social (hipotético ou real); a inclusão e o desenvolvimento social ou nacional; e o desenvolvimento livre das esferas institucionais. Não obstante as respostas sociais dominantes da religião e da secularidade serem alvo de tensão e de negociação permanente, a todos os problemas de referência é oferecida normalmente uma solução baseada em ideias-guiadoras seculares.

A hegemonia e institucionalização destas ideias guiadoras e a sua aplicação aos problemas de referência, seguindo a terminologia de Wohlrab-Sahr e Burchardt (2012), levaram à emergência de culturas de secularidade que são codificadas no direito, construídas dialeticamente no espaço público e compreendidas nos hábitos culturais das pessoas. Isto transformou-as num grupo de pressupostos dominantes que moldam as perceções, práticas e sensibilidades dos indivíduos no concernente à religião.

Em suma, com a pressão hodierna dos problemas de referência, os Estados (por imperativos de racionalidade ou eficiência) constrangem os princípios e as práticas religiosas, institucionalizando-os, para que fiquem o mais confinados possível ao respeito pelos princípios democráticos. As sociedades demo- cráticas passam, no espaço público, a viver sobretudo de referências seculares e, com isto, diminuem-se os níveis de literacia religiosa e o papel das religiões nas práticas quotidianas dos indivíduos.

\section{Relações Estado-religiões e liberdade religiosa em Portugal}

Existe uma longa tradição política em Portugal de relações, sobretudo, com a Igreja Católica, desde 0 ato de vassalagem de 1143, passando pelas onze concórdias do período 1210-1642, até às inúmeras concordatas assinadas durante a formação do território (Leite, 1993, p. 13-22). A falta de experiências pluralistas no campo religioso (por exemplo, protestantismo), tanto na corte como no povo, conduziu a que, na Monarquia Constitucional (1820-1910), o catolicismo passasse a ser a religião oficial do Estado.

Sistematizando essa inevitável ligação confessional, o artigo $25 .{ }^{\circ}$ da Constituição de 1822 afirmava que "a religião da Nação Portuguesa é a católica apostólica romana". As três Constituições da Monarquia liberal teriam, aliás, em comum a afirmação do catolicismo como religião oficial do Estado - artigo $25 .^{\circ}$ da Constituição de 1822; artigo $6 .^{\circ}$ da Constituição de 1826 ; e artigo $3 .^{\circ}$ da Constituição de 1838 -, indo a Carta de 1826 um pouco mais longe no seu espírito ao afirmar, no n. 04 do artigo 145. ${ }^{\circ}$, que "ninguém pode ser perseguido por motivos de Religião, uma vez que respeite a do Estado e não ofenda a Moral Pública". Assim seria até 5 de outubro de 1910 .

A proclamação da República foi acompanhada dum conflito religioso, ligado à reação contra o anterior sistema de união, derivado dum anticlericalismo difuso em certos sectores da população urbana e do positivismo e jacobinismo do Partido Republicano. Não foi, portanto, de estranhar que a legislação dos primeiros meses do novo regime assumisse uma posição "vincadamente laicista e anticatólica" (Miranda, 1986, p. 120).

Neste sentido, foi publicado o decreto com força de lei de 20 de abril de 1911 ("Lei da Separação da Igreja e do Estado"), no qual o artigo 2.0 preceituava que "a religião católica apostólica romana deixa de ser a religião do Estado e todas as religiões são igualmente autorizadas". Assim, não só pela primeira vez o Estado e a religião apareceram dissociados, porquanto foi eliminada a religião do Estado, como também a religião católica surgiu em igualdade com as demais confissões, no que concerne quer ao culto particular, quer ao próprio culto público. A Constituição de 1911 consagrava ainda, no título respeitante aos direitos e garantias individuais (artigo 3. ${ }^{\circ}$, n. ${ }^{\circ} 6$ a 12; e artigo 4. ${ }^{\circ}$, na continuidade da Lei da Separação, a não confessionalidade do Estado e a plena liberdade de consciência de todos os cidadãos. 
Já durante o Estado Novo, a Constituição de 1933, no seu artigo 8. ${ }^{\circ}$, n. ${ }^{\circ} 3$, entre os direitos e garantias individuais dos cidadãos portugueses, mencionava a liberdade e inviolabilidade de crenças e práticas religiosas, não podendo ninguém por causa delas ser perseguido, privado dum direito ou isento de qualquer obrigação ou dever cívico, acrescentando também que ninguém seria obrigado a responder acerca da religião que professava. No título respeitante às relações do Estado com a Igreja Católica e demais cultos inscreviam-se os artigos $45 .^{\circ}$ e $46 .^{\circ}$, nos quais, além do mais, se dispunha ser livre o culto público ou particular de todas as religiões, e ainda que, sem prejuízo do preceituado pelas concordatas, o Estado mantinha o regime de separação em relação à Igreja Católica e a qualquer outra religião ou cultos praticados dentro do território português. No entanto, em 7 de maio de 1940, foi assinada a concordata entre a Santa Sé e a República Portuguesa, de cujas disposições mais significativas se verifica que, de um lado, houve o propósito de não voltar ao sistema da religião oficial do Estado, mas, de outro, não se hesitou em reconhecer e garantir uma posição especial para a religião católica.

Isto fica em evidência na revisão constitucional de 1951, onde, através da nova redação do artigo $45 .{ }^{\circ}$, se considerou o catolicismo como "a religião da Nação portuguesa". Apesar da permanência do princípio da separação na relação entre o Estado e a Igreja Católica, o tratamento diferenciado à instituição colocou-a numa situação de supremacia face às outras confissões religiosas (Miranda, 1993, p. 78).

De facto, durante este período, nomeadamente entre 1933 e 1971, as minorias religiosas tiveram dificuldades de representação formal ou simbólica ao nível político. Tanto a comunidade judaica (ultraminoritária no universo religioso português) como a protestante (discriminada em matéria de educação e ensino) e, dentro dela, as Testemunhas de Jeová (perseguidas e acusadas de atuar contra a segurança estatal) ou a Federação Espírita Portuguesa (ilegalizada em 1953) foram afastadas ou não conseguiram fazer prevalecer os seus interesses no espaço público.

Com a morte de Salazar em 1968 e a ascensão de Marcello Caetano, surge uma nova fase do ordenamento da lei da liberdade religiosa em Portugal. É publicada a lei n. ${ }^{\circ}$ 4/71 que prevê um sistema de reconhecimento das confissões não católicas, inexistente até então (Miranda, 1993, p. 78-79). Na sua Base II, a lei afirma que o Estado não professa qualquer religião e que as suas relações com as confissões religiosas assentam no regime de separação, acrescentando que as confissões religiosas têm direito a igual tratamento, ressalvando as diferenças impostas pela sua diversa representatividade.
Com a queda do regime em 1974 e os inícios da democratização do país, a Constituição da República Portuguesa (CRP) de 1976 veio garantir a liberdade religiosa sem aceção de confissões e sem quaisquer limites específicos. Tornou-se num estádio mais avançado do que os sucessivos regimes anteriores de união, neutralidade laicista e relação preferencial com a Igreja Católica, servindo a separação essencialmente de garantia da liberdade e da igualdade (Miranda, 1986, p. 123). Cabe, enfim, fazer uma nota sobre a manutenção da Concordata de 1940, a seguir à Revolução de 25 de Abril de 1974.

A transição democrática e a CRP abriram portas a um novo Portugal. Todavia, as relações com a Igreja Católica mantiveram-se idênticas (no plano formal). A vigência dos diplomas legais de 1940 seria apenas tocada pelo protocolo adicional de 1975, perdurando até ao século XXI, quando a Lei da Liberdade Religiosa (LLR) de 2001 conduziu Estado e Igreja Católica para uma nova concordata nascida em 2004. Com efeito, o sistema de relações Estado-religiões implementado pela CRP assumiu a neutralidade, a igualdade de tratamento e a separação entre Estado e confissões religiosas (artigo 41. ${ }^{\circ}$ ).

A liberdade religiosa surgiu, então, associada à liberdade de consciência, não obstante as suas diferenças já citadas. Assim sendo, estabeleceu-se a liberdade de manifestação religiosa, separadamente ou em conjunto, em público ou em privado, através do ensino, da prática, do culto ou dos ritos - em consonância com o artigo $18 .^{\circ}$ da Declaração Universal dos Direitos Humanos. Foram assim garantidos, no n. ${ }^{\circ} 2$ do artigo $41 .{ }^{\circ}$, os direitos e obrigações ou deveres cívicos, independentemente das convicções e práticas religiosas; no n. ${ }^{3}$, a proteção do sigilo da opção religiosa individual; e no n. ${ }^{\circ} 6$, a objeção de consciência por motivos de crença ou convicção. A LLR, no n. ${ }^{\circ} 1$ do artigo 4. ${ }^{\circ}$, afirmou o princípio da não confessionalidade do Estado, mas também a cooperação com as igrejas e comunidades religiosas radicadas em Portugal (artigo 5.․), a aplicação do princípio da tolerância para salvaguardar a liberdade de cada crença (artigo $7 .{ }^{\circ}$ ) e a proteção dos direitos individuais e coletivos de liberdade religiosa (artigo 8. ${ }^{\circ}$ e seguintes).

Não obstante as vicissitudes históricas do modelo vigente de separação Estado-religiões, Portugal tem hoje um quadro legal geral de liberdade religiosa. Todavia, como acontece noutras constituições, a CRP possui uma cláusula de estado de exceção, reservada a moldar a ordem jurídica constitucional a períodos de crise. Com efeito, a CRP (n. ${ }^{\circ} 6$ do artigo 19. ${ }^{\circ}$ ) afirma, sobre a suspensão do exercício de direitos, que o estado de sítio ou de emergência em nenhum caso pode afetar a liberdade de consciência e de religião ${ }^{1}$. Ao nível subconstitucional, a LLR reforça esse princípio no n. ${ }^{\circ} 5$ do artigo 6. ${ }^{\circ}$. Como atestam vários constitu- 
cionalistas, a liberdade de religião integra o âmago dos direitos pessoais, não podendo ser sacrificada nem sequer em caso de estado de sítio (Medeiros \& Miranda, 2010, p. 893; Raimundo, Adragão, Leão \& Ramalho 2020, p. 6). A jurisprudência reforça esta ideia, afirmando que a liberdade de religião é também insuscetível de suspensão em estado de sítio ou emergência, constituindo um limite material de revisão constitucional².

Contudo, como sublinham Raimundo, Adragão, Leão e Ramalho (2020, p. 7), esta interpretação gera "interrogações", uma vez que a CRP (n. ${ }^{\circ} 1$ do artigo $\left.41 .^{\circ}\right)$ permite a distinção entre liberdade religiosa - liberdade de crença ou não crença - e liberdade de manifestação exterior e prática de atos de culto. Como se verá na secção subsequente, durante o estado de emergência, o direito de culto não foi considerado como direito intangível, sendo essa condição garantida apenas à liberdade de crença.

\section{Era secular e pandemia em Portugal}

À semelhança da maioria dos países europeus, Portugal abriu a possibilidade de as autoridades imporem restrições à realização de celebrações religiosas ou outros eventos de culto que implicassem aglomeração de pessoas. O Decreto n. ${ }^{\circ}$ 2-A/2020, de 20 de março, procedeu à execução da declaração do estado de emergência efetuada pelo Decreto n.o 14-A/2020, de 18 de março. No seu artigo $17 .{ }^{\circ}$, sobre eventos de cariz religioso e culto, estabeleceu-se que ficava "proibida a realização de celebrações de cariz religioso e de outros eventos de culto que impliquem uma aglomeração de pessoas". Além disso, ficou estipulado que a realização de funerais estava "condicionada" à adoção de medidas que "garantam a inexistência de aglomerados de pessoas e o controlo das distâncias de segurança (...) a determinar pela autarquia local que exerça os poderes de gestão do respetivo cemitério".

O Decreto n. ${ }^{\circ}$ 17-A/2020, de 2 de abril, que renovou a declaração de estado de emergência, com fundamento na verificação de uma situação de calamidade pública, estendeu essas restrições. Na alínea f) do artigo $4 .{ }^{\circ}$ do Anexo II, afirmou que ficava parcialmente suspenso o direito à liberdade de culto, "na sua dimensão coletiva", podendo ser "impostas pelas autoridades públicas competentes as restrições necessárias para reduzir o risco de contágio e executar as medidas de prevenção e combate à epidemia", compreendendo a "limitação ou proibição de realização de celebrações religiosas" que, novamente, implicassem uma aglomeração de pessoas. Ficou ressalvado, no n. 01 do artigo 7.0, que esta declaração não afetaria o direito à liberdade de consciência e religião ${ }^{3}$.

Como afirma o Relatório sobre Liberdade Religiosa no Mundo (ACN Internacional, 2021, p. 3), na ficha sobre Portugal, um dos efeitos do combate à covid-19 foi a restrição de celebrações religiosas no espaço público. Todavia, como previamente mencionado, o nível de restrição ao culto religioso em Portugal foi elevado, quando comparado com os demais países europeus (The Conversation, 2020), tendo sido marcado por elevada restritividade, suspensão de celebrações religiosas e abertura de espaços de culto apenas para práticas cultuais individuais.

Houve, à semelhança do teorizado por Wohlrab-Sahr e Burchardt (2012), uma aplicação da secularidade em nome de questões de saúde pública. Ou seja, ao problema de referência (pandemia) ofereceram-se respostas seculares (restrições ao culto), respeitando princípios seculares, tais como: racionalidade, ciência, individualidade ou afastamento físico ${ }^{4}$. Isso vai ao encontro do n. ${ }^{0} 2$ do artigo $18 .^{\circ}$ da $\mathrm{CRP}$, onde vem plasmado que a restrição de direitos, liberdades e garantias só poderá ser feita através da lei, quando adequado, necessário e proporcional em sentido estrito, para salvaguardar direitos ou interesses constitucionalmente protegidos.

O argumento de Wohlrab-Sahr e Burchardt (2012) é também visível no modo como as práticas cultuais só abriram na última fase do plano de desconfinamento proposto pelo governo português. Aí estava previsto que as cerimónias religiosas abririam a 30-31 de maio de 2020, com celebrações comunitárias de acordo com regras a definir entre a Direção Geral da Saúde (DGS) e as confissões religiosas. Nessa mesma data desconfinariam, igualmente, as competições de futebol (jogos oficiais de futebol da Primeira Liga e Taça de Portugal). Antes dessa data, desconfinariam, prioritariamente: i) transportes públicos, comércio local (por exemplo, cabeleireiros e manicures), certos serviços públicos (por exemplo, balcões de finanças ou conservatórias) ou a prática de desporto ao ar livre (4 de maio); e ii) restaurantes, cafés e pastelarias, museus e monumentos nacionais ou equipamentos sociais na área da deficiência (18 de maio).

As escolhas de hierarquização efetuadas pelo Estado, através do sistema de (des)confinamento, "não são neutras", segundo Ferrière (2020, p. 9). Ou seja, a hierarquização de atividades essenciais e não essenciais no regime de confinamento tem um âmbito normativo, sendo regida por critérios científicos que, neste caso, priorizaram a biopolítica, sobretudo, nos seus diferentes dispositivos: médico, económico e securitário. O sistema de confinamento opera, portanto, sob uma lógica de desvalorização de certos valores simbólicos, nomeadamente os associados à subjetividade e à crença, em detrimento doutros associados à racionalidade e à objetividade.

O desenvolvimento e hegemonia de culturas de secularidade que reclamam a primazia da autoridade política, racional e secular fica aqui evidenciado. $\mathrm{Na}$ 
linha de Berger (1990 [1967]), o desenvolvimento destas hegemonias seculares, entre outros aspetos, ajuda a relativizar qualquer corpo de crenças religiosas, minando a inquestionabilidade das suas estruturas de plausibilidade. Bruce vai mais longe, ao enfatizar que a afirmação e a hegemonia de princípios e práticas seculares visam "substituir os religiosos" (Bruce, 2014, p. 192), levando a um esvaziamento da religião no espaço público, em particular ao nível do "controlo das interações quotidianas" (Bruce, 2011, p. 37) e, por conseguinte, a uma agudização da crise das suas estruturas de plausibilidade.

No concernente a este ponto, Raimundo, Adragão, Leão e Ramalho (2020, p. 31) afirmaram:

"[É] discutível se na construção das medidas [de contenção da pandemia], se deu sempre a ponderação que seria devida à liberdade religiosa - designadamente, quando se assistiu à retoma de diversas actividades económicas não essenciais, que envolvem aglomeração de pessoas, num ritmo mais acelerado do que as celebrações religiosas."

Estes elementos são mais controvertidos por conta de questões sobre a legitimidade conferida a uma autoridade de saúde, administrativa, para ajudar a suspender o direito à liberdade religiosa e à circulação de pessoas. A CRP "veda" ( $n .{ }^{\circ} 1$ do artigo $45 .{ }^{\circ}$ ) a possibilidade de se limitar a liberdade de reunião, incluindo a de culto, pelo seu carácter normativo idêntico, através de uma autorização administrativa. Gouveia (2020) vai mais longe, afirmando que o direito ao culto religioso é "insuspensível, não se distinguindo entre liberdade religiosa coletiva ou individual", dado que a liberdade religiosa engloba direitos individuais e coletivos.

Todavia, nem sob o espectro da possível inconstitucionalidade e desproporcionalidade das medidas relacionadas com a suspensão das cerimónias religiosas comunitárias - i.e., mesmo com o avanço da secularidade para o bem da saúde pública, com as características previamente enunciadas - as principais igrejas e comunidades religiosas radicadas em Portugal se manifestaram contra as regras impostas. Pelo contrário, à semelhança do teorizado por Luckmann (1967) e Dobbelaere (1981), houve lugar a uma secularização interna ou organizacional, respetivamente, onde as igrejas e comunidades religiosas procuraram adaptar-se às condições modernas e às exigências de racionalização, privatização da crença e afastamento. O caso da Igreja Católica é elucidativo do modo como a hegemonia secular foi bem-recebida e promovida pelas igrejas e comunidades religiosas presentes no país. Mesmo antes do Decreto do Governo que veio regulamentar o estado de emergência, n. ${ }^{\circ}$ 14-A/2020, de 18 de março, ou das orientações do Vaticano ${ }^{5}$, a Conferência Episcopal Portuguesa (CEP) emitiu uma Nota do seu Conselho Permanente, de 2 de março, sobre a situação provocada pelo coronavírus, onde pediu aos fiéis que seguissem "estritamente as indicações e normas da Direção Geral de Saúde", alertando para algumas "medidas de prudência" em celebrações e espaços litúrgicos (Conferência Episcopal Portuguesa, 2020a). No Comunicado de 13 de março sobre a covid-19, a CEP foi mais além, determinando que os "sacerdotes suspendam a celebração comunitária da Santa Missa até ser superada a atual situação de emergência" (Conferência Episcopal Portuguesa, 2020b). A pandemia conduziu, assim, a Igreja Católica portuguesa a decidir pela suspensão de todas as missas em território nacional. Segundo os bispos portugueses, estas medidas deveriam ser "complementadas com as possíveis ofertas celebrativas na televisão, rádio e internet". O constitucionalista Bacelar Gouveia (Público, 2020) referiu, a este respeito, que a Igreja Católica "não esteve bem", porquanto foi "mais drástica do que o poder político, tomando e até antecipando uma proibição que nem o próprio Estado teve a ousadia de aplicar com tanta severidade".

Além do elogio à prática religiosa individual, no lar, à mediação digital das celebrações religiosas, ao respeito pelas normas estabelecidas pelas autoridades políticas ou administrativas competentes, como a DGS, a Igreja Católica manteve a suspensão de peregrinações e romarias. Isso incluiu a Peregrinação Internacional Aniversária ao Santuário de Fátima (13 de maio), que deveria decorrer sem a presença de assembleia.

Esta conduta de secularização interna ou organizacional foi seguida, com as respetivas especificidades, pelas demais igrejas e comunidades religiosas radicadas em Portugal. Por exemplo, a Comunidade Islâmica de Lisboa encerrou a Mesquita Central de Lisboa durante o estado de emergência, procedendo igualmente à suspensão de todas as aulas e da oração de sexta-feira (Salatul-Jumu'ah). Num comunicado pediu-se que se cumprissem "rigorosamente as recomendações das autoridades (...), nomeadamente da DGS", alertando para a hipótese de se "repensar" as "práticas e procedimentos habituais" do mês Sagrado do Ramadão (Comunidade Islâmica de Lisboa, 2020). Por seu turno, a Comunidade Israelita de Lisboa, afirmou que procederia a "uma inevitável adaptação" dos seus serviços e estrutura comunitária, bem como à "suspensão" das suas principais atividades. Foi encerrada a sinagoga, sendo também suspensos "todos os serviços religiosos (...) por tempo indeterminado" (Comunidade Israelita de Lisboa, 2020). Finalmente, a Aliança Evangélica Portuguesa (AEP) recomendou que igrejas e comunidades evangélicas não abrissem "portas para cultos e outras ativi- 
dades", pedindo respeito por "todas as indicações sanitárias da DGS" (Aliança Evangélica Portuguesa, 2020). Entre outros, o mesmo sucedeu com as Testemunhas de Jeová, Igreja Católica Ortodoxa de Portugal, União Portuguesa dos Adventistas do Sétimo Dia e Mórmons.

À semelhança da Igreja Católica portuguesa, houve ainda uma recomendação transversal a todas igrejas e comunidades religiosas para o culto doméstico, individual ou no ambiente familiar, e um apelo à utilização de meios de comunicação digital. Para os católicos, as medidas adotadas pela igreja deveriam ser "complementadas com as possíveis ofertas celebrativas na televisão, rádio e internet", devendo-se permanecer em "oração pessoal e familiar" (Conferência Episcopal Portuguesa, 2020c). Por sua vez, a Comunidade Islâmica de Lisboa passou o Duá, uma parte essencial do culto, para o Facebook; as Testemunhas de Jeová apelaram à leitura online da Bíblia e à partilha de conteúdos bíblicos digitais; a AEP recomendou o uso da tecnologia para transmitir as celebrações ou gravar mensagens/pregações; e os adventistas passaram os seus serviços de culto para o seu sítio de internet.

$\mathrm{Na}$ formulação de Wohlrab-Sahr e Burchardt (2012), previamente analisada, o poder de agência sobre as culturas de secularidade - neste caso, em favor de questões de saúde pública - está centrado nas autoridades públicas seculares. Na era secular, esse fenómeno promove uma competição religioso-secular cujo terreno de jogo é desnivelado a favor de princípios duma ordem moral moderna secular. Todavia, o que se verificou na experiência portuguesa foi uma corresponsabilização do secular e do religioso para o desenvolvimento de respostas seculares a um problema de referência específico (pandemia). Mesmo antes da promoção ou imposição do poder político, foram as próprias igrejas e comunidades religiosas a favorecer uma tal ordem moral moderna secular, promovendo uma auto-secularidade que presume a subordinação de valores e práticas religiosas aos da esfera política.

Em parte, isto reflete o que o Relatório sobre Liberdade Religiosa no Mundo (ACN International, 2021, p. 4) descreve sobre Portugal quando afirma que alguns fenómenos, típicos das sociedades hodiernas ocidentais, chegaram ao país, particularmente a crescente "marginalização da religião na vida pública e a legalização de práticas" opostas aos valores de várias religiões. Na conceção tayloriana, como visto, este tipo de práticas reflete um quadro ou referencial imanente (secular), no qual, por exemplo, a ciência e a tecnologia se assumem como marco cósmico e ontológico que rege as sociedades modernas.

Mesmo com a transição do religioso para a esfera digital, tendência que se tem vindo a afirmar como complemento das práticas religiosas, as novas tecnologias podem constituir um elemento de "diluição das comunidades religiosas", segundo Franca, Martins e Fernandes (2019, p. 135). Elas contribuem para a alteração das sociabilidades assentes na vizinhança residencial e numa única comunidade física e aumentam a complexidade das relações socioespaciais, sobretudo, no espaço urbano. Como discutido noutros locais (Hervieu-Léger, 1999; Moniz, 2020; Wilson, 1969 [1966]), o declínio das formas de comunidade e a consequente atomização dos indivíduos tendem a afastar as pessoas dos laços comunitários religiosos tradicionais. Promovem esferas privadas e móveis de interação social que fomentam a diminuição da plausibilidade global dos sistemas moral e religioso (tradicionais). Esta cultura de secularidade, também promovida pelas igrejas e comunidades religiosas, tende a difundir uma religiosidade com vínculos institucionais mais ténues e sem efeitos praxistas que pode ter consequências negativas para a religião, nomeadamente a sua desagregação e acantonamento. Isto é especialmente evidente na sua coparticipação no espaço público, amiúde dispersa e fortemente controlada pela esfera política.

\section{Considerações finais}

Num comentário final, podemos afirmar que a normalização da preponderância dos princípios seculares permitiu uma hierarquização de atividades essenciais e não essenciais que, além de desafiar as estruturas de plausibilidade da religião, esvaziou a sua presença no espaço público e ajudou a promover uma cultura de secularidade. É provável que isto tenha sucedido por conta do quinteto de razões prévia e implicitamente examinadas e que agora se explicitam:

- o gradual predomínio duma era secular que assume um afastamento da religião no espaço público;

- o estabelecimento dum sistema de relações Estado-religiões que implementa processos de regulação/controlo do religioso baseados em princípios de neutralidade secular e numa lógica de hierarquização que tende a desvalorizar certos valores simbólicos (religiosos);

- o avanço e hegemonia de culturas de secularidade que reclamam a primazia da autoridade política, racional e secular; neste caso, através do avanço da secularidade para o bem da saúde pública;

- a aceitação da subordinação de princípios e experiências religiosas aos da esfera política através da promoção de uma auto-secularidade, promovida pelas igrejas e comunidades religiosas, que favorece a ordem moral moderna secular;

- a passagem do religioso para a esfera privada e digital, que reduz os vínculos comunitá- 
rios tradicionais e tende a disseminar uma religiosidade com laços institucionais mais frágeis e sem efeitos praxistas.

O quinteto de asserções e as construções teóricas que Ihes subjazem não são, porém, sinónimos dum perecimento da religião, sendo ainda menos tributários da ideia de que isso poderá suceder duma forma universal, unilinear ou determinista. Não obstante o avanço duma era secular, marcada pela emergência e predomínio dum paradigma imanente de interpretação do mundo e pelo avanço e hegemonia de culturas de secularidade, a religião continua a ser importante. Como evidenciado, nos casos referentes à manutenção da realização de celebrações de carácter religioso, de funerais ou da liberdade de circulação dos ministros de culto, pese embora as suas múltiplas condicionantes, a própria cultura de secularidade foi forçada a adaptar-se ao religioso.

Todavia, aquando da resposta aos problemas de referência específicos das sociedades hodiernas, como visto, tanto na teoria como na prática, a solução oferecida baseia-se unicamente em ideias-guiadoras seculares. Por exemplo, ao problema de referência da covid-19 deu-se uma resposta secular, i.e., a restrição da liberdade de manifestação exterior e da prática de atos de culto. Priorizou-se a privatização da crença ao invés do culto religioso, o afastamento físico ao invés da eclésia e a racionalidade e conhecimento científico ao invés da fé ou tradição. Apesar de, mesmo dentro das culturas de secularidade, o político permitir ao religioso influenciar propostas de significado sociopolítico, a premissa é de que as fontes inspiradoras da religião apareçam amortecidas.

Por fim, não pretendo diminuir a relevância do trabalho aqui desenvolvido, até porque, modéstia à parte, considero-o profícuo para enquadrar a era secular, desafiar as culturas de secularidade e lançar novas pistas de investigação na área. Mais, esta investigação anima o futuro debate sobre as consequências, positivas ou negativas, da auto-secularidade fomentada durante a pandemia. Contudo, serão necessários mais estudos para sustentar este argumento ou para falsificá-lo. Serão indispensáveis mais investigações, provavelmente com maior amplitude e abrangência, que considerem outras áreas geográficas, métodos comparativos e períodos de análise mais extensos. Todavia, neste momento, apenas posso esperar que este estudo seja um contributo nesse sentido.

\section{Notas}

1 Cf. Lei n. $044 / 86$, de 30 de setembro, sobre o regime do estado de sítio e do estado de emergência. O n.o 1 do artigo 2. ${ }^{\circ}$, sobre garantias dos direitos dos cidadãos, diz precisamente o mesmo.
2 Cf. Processo 01394/06.0BEPRT, Acórdão n. ${ }^{0}$ 544/2014 e Acórdão n.o 545/2014.

3 Recorde-se que o Despacho n. ${ }^{\circ}$ 4235-D/2020, sobre a aplicação do artigo $6 .^{\circ}$ do Decreto n. ${ }^{\circ} 2-B / 2020$ aos ministros do culto, Ihes garantiu a "liberdade de circulação para a prática de atos urgentes, ainda que enquadrada nos condicionalismos gerais vigentes". Ou seja, reafirmou a manutenção das limitações à dimensão coletiva da liberdade de culto, previstas na alínea f) do artigo 4. ${ }^{\circ}$ do mesmo Decreto.

4 De acordo com a matriz de formas básicas de secularidade (Wohlrab-Sahr \& Burchardt, 2012, p. 890), este tipo de secularidade, a favor de questões de saúde pública, afigura-se mais próximo daquele de tipo 1 (associado ao mundo da vida e com foco implícito centralizado), onde a secularidade é acompanhada de ideias guiadoras como a responsabilidade individual e o afastamento físico. Aproxima-se ainda da secularidade do tipo 4 (associada ao sistema e com foco implícito descentralizado), onde a secularidade é acompanhada de ideias guiadoras como a racionalidade e o conhecimento científico.

5 Decretos "Em tempo de COVID-19", de 19 de março, e "Em tempo de COVID-19 II", de 25 de março.

\section{Referências bibliográficas}

ACN International. (2021). Liberdade religiosa no mundo - Relatório 2021: Portugal. Retirado de https://rfr. acninternational.org/wp-content/uploads/2021/05/ Portugal.pdf.

Raimundo, M. A., Adragão, P. P., Leão, A. C., \& RamaIho, T. (2020). Covid-19 e liberdade religiosa em Portugal. Revista General de Derecho Canónico y Derecho Eclesiástico del Estado, 54, 1-31.

Aliança Evangélica Portuguesa (AEP). (2020). Coronavírus - Recomendações/Palavras do Presidente da AEP, 13 de março. Retirado de https://aliancaevangelica.pt/site/2020/03/13/covid-19_aep/.

Berger, P. L. (1979). The heretical imperative: Contemporary possibilities of religious affirmation. Norwell: Anchor Press.

Berger, P. L. (1990 [1967]). The sacred canopy: Elements of a sociological theory of religion. Nova Iorque: Anchor Books.

Berger, P. L., Davie, G., \& Fokas, E. (2008). Religious America, secular Europe?: A theme and variation. Aldershot: Ashgate Publishing.

Bruce, S. (2011). Secularization: In defence of an unfashionable theory. Oxford: UP Oxford.

Bruce, S. (2014). History, sociology, and secularization. In C. Hartney (ed.), Secularisation: New historical perspectives (pp. 190-213). Cambridge: Cambridge Scholars Publishing.

Casanova, J. (1994). Public religions in the modern world. Chicago: University of Chicago Press.

Comunidade Islâmica de Lisboa. (2020). Comunicado do Presidente da Comunidade Islâmica de Lisboa, 20 de março. Retirado de https:// www. facebook.com/comunidadeislamica/photo s/a.1129477503741813/2903949359627943/. 
Comunidade Israelita de Lisboa. (2020). Comunicado COVID-19, 19 de março. Retirado de https://www.facebook.com/cilisboa/photo s/a.138737956176265/3037148753001823/.

Conferência Episcopal Portuguesa. (2020a). Coronavírus: Nota do Conselho Permanente da CEP, 2 de março. Retirado de https://agencia.ecclesia.pt/ portal/coronavirus-nota-do-conselho-permanente-da-cep/.

Conferência Episcopal Portuguesa. (2020b). Covid-19 - Comunicado da Conferência Episcopal Portuguesa, 13 de março. Retirado de https://www. conferenciaepiscopal.pt/v1/covid-19-comunicado-da-conferencia-episcopal-portuguesa/.

Conferência Episcopal Portuguesa. (2020c). Covid19: Conferência Episcopal determina suspensão da celebração comunitária das Missas, 13 de março. Retirado de https://agencia.ecclesia.pt/ portal/covid-19-conferencia-episcopal-portuguesa-determina-suspensao-da-celebracao-comunitaria-das-missas/.

Dobbelaere, K. (1981). Secularization: A multi-dimensional concept. Current Sociology, 29(2), 3-153.

Ferrière, A. (2020). Religion et sécularisme au temps du coronavirus. Retirado de https://www.pug. $\mathrm{fr} /$ produit/1821/9782706148798/religion-et-secularisme-au-temps-du-coronavirus/preview ?escape $=$ false $\# \mid \mathrm{g}=1$ \& slide $=0$.

Franca, M., Martins, R., \& Fernandes, J. L. (2019). Práticas religiosas e redes sociais. Os novos espaços e tempos da Igreja Católica em Portugal. Sociologia On Line, 21, 116-140.

Gouveia, J. B. (2020). Estado de emergência. AEFDUNL, 16 de abril. Retirado de https://www.youtube. com/watch?v=PaZKOroZuEo.

Hervieu-Léger, D. (1999). La religion en mouvement: Le pèlerin et le converti. Paris: Flammarion.

Luckmann, T. (1967). The invisible religion: The problem of religion in modern society. Nova Iorque: Macmillan.
Luhmann, N. (2013 [1998]). A systems theory of religion (Cultural memory in the present). Stanford: Stanford University Press.

Medeiros, R., \& Miranda, J. (2010). Constituição portuguesa anotada, Tomo I - Introdução geral e preâmbulo, artigos $1 .^{\circ}$ a $79.0^{\circ}$ (2. a ed.). Coimbra: Coimbra Editora.

Miranda, J. (1986). Liberdade religiosa, igrejas e Estado em Portugal. Nação e Defesa, XI(39), 119-136.

Miranda, J. (1993). A concordata e a ordem constitucional portuguesa. In Universidade Católica Portuguesa (ed.), A concordata de 1940, Portugal - Santa Sé (pp. 67-84). Lisboa: Edições Didaskalia.

Moniz, J. B. (2020). Societalização como secularização? Correlação entre os índices de societalização e religiosidade na Europa. Revista Colombiana de Sociología, 43(1), 235-260.

Moniz, J. B. (2021). Secularização na AML: Deslocação, recomposição ou fragmentação da religião?. In A. Teixeira (ed.), Religião, território e identidade. Lisboa: INCM (no prelo).

Pace, E. (2017). Systems theory and religion. Civitas, $17(2), 345-359$.

Público. (2020). Questões para a renovação do estado de emergência, 1 de abril. Retirado de https:// www.publico.pt/2020/04/01/politica/opiniao/ questoes-renovacao-estado-emergencia-1910132.

Taylor, C. (2007). A secular age. Cambridge: Harvard University Press.

The Conversation. (2020). Coronavirus: How new restrictions on religious liberty vary across Europe, 9 de abril. Retirado de https://theconversation.com/ coronavirus-how-new-restrictions-on-religious-liberty-vary-across-europe-135879.

Wilson, B. (1969 [1966]). Religion in secular society: A sociological comment, Harmondsworth: Penguin Books.

Wohlrab-Sahr, M., \& Burchardt, M. (2012). Multiples secularities: Toward a cultural sociology of secular modernities. Comparative Sociology, 11, 875-909. 